\title{
O Plano de Saneamento da Amazônia (1940-1942)
}

\author{
The Amazon Sanitation Plan (1940-1942)
}

Rômulo de Paula Andrade

Doutorando do Programa de Pós-graduação em História das Ciências e da Saúde/Casa de Oswaldo Cruz/Fundação Oswaldo Cruz

Av. Brasil, 4036

21040-361 - Rio de Janeiro - RJ

Brasil

romulopa@hotmail.com

Gilberto Hochman

Casa de Oswaldo Cruz/ Fundação Oswaldo Cruz Av. Brasil 4036/403

21040-361 - Rio de Janeiro - RJ

Brasil

hochman@coc.fiocruz.br
ANDRADE, Rômulo de Paula; HOCHMAN, Gilberto. O Plano de Saneamento da Amazônia (1940-1942). História, Ciências, Saúde - Manguinhos, Rio de Janeiro, v.14, suplemento, p.257-277, dez. 2007.

Aborda o Plano de Saneamento da Amazônia e o contexto político de sua formulação, entre 1940 e 1941, o papel de Getúlio Vargas, a atuação de seus principais protagonistas como Evandro Chagas, João de Barros Barreto e Valério Konder, as suas principais propostas e o seu ocaso a partir de 1942, por conta da criação do Serviço Especial de Saúde Pública (SESP), fruto dos acordos de cooperação entre Brasil e Estados Unidos, com o envolvimento de ambos na Segunda Guerra Mundial. Inclui a reprodução do Plano publicado em dezembro de 1941 nos Arquivos de Higiene.

PALAVRAS-CHAVE: Amazônia; saúde; saneamento; Getúlio Vargas; malária; Barros Barreto.

ANDRADE, Rômulo de Paula; HOCHMAN, Gilberto. The Amazon Sanitation Plan (1940-1942). História, Ciências, SaúdeManguinhos, Rio de Janeiro, v.14, supplement, p.257-277, Dec. 2007.

The article addresses the Amazon Sanitation Plan and the political context in which it was formulated between 1940 and 1941. It examines the role of Getúlio Vargas, the activities of the plan's main protagonists (such as Evandro Chagas, João de Barros Barreto, and Valério Konder), its key proposals, and its demise as of 1942 upon creation of the Special Public Health Service (Sesp), which grew out of cooperation agreements between Brazil and the US following both nations' involvement in World War II. A reproduction of the Plan as published in the Arquivos de Higiene in 1941 is included.

KEYWORDS: Amazon; health; sanitation; Getúlio Vargas; malaria; Barros Barreto. 


\section{Os preparativos}

o longo da década de 1930, intelectuais e médicos apontavam
a malária como o grande obstáculo para o desenvolvimento
discursos políticos buscavam chamar a atenção do governo federal
sobre as condições de saúde da região. Após o golpe do Estado
Novo, em novembro de 1937, a Amazônia ganhou relevância para
o governo Vargas, principalmente a partir da Marcha Para o Oeste
(1938), programa de governo que buscava a integração econômica
nacional a partir da colonização de regiões consideradas longín-
quas e desabitadas (Andrade, 2007, p.43-65). A partir de outubro
de 1940, com a viagem de Getúlio Vargas à Amazônia, a região
tornou-se estratégica no discurso do regime.

No primeiro semestre de 1940, o médico Evandro Chagas, que já trabalhava na região, recebeu solicitação do Ministério da Educação e Saúde para investigar o problema de malária nos estados do Amazonas e Pará, tendo em vista a viagem de Getúlio Vargas prevista inicialmente para agosto do mesmo ano. ${ }^{1}$ Nesse trabalho foram mobilizadas duas instituições científicas que atuavam na região desde os anos 30 e eram capitaneadas por Evandro Chagas: o Instituto de Patologia Experimental do Norte (Ipen), fruto da cooperação entre os serviços sanitários paraense e federais, sob orientação do Instituto Oswaldo Cruz (IOC) e do Serviço de Estudo das Grandes Endemias (Sege), este vinculado àquele (Andrade, 2007; Kropf, 2006)

Evandro pretendia iniciar os trabalhos no decorrer do ano de 1940, fazendo um estudo geral da incidência de malária através de inquéritos a serem realizados nas cidades situadas às margens do rio Amazonas e seus principais afluentes. Antes, porém, foi assinado um acordo entre a $2^{\text {a }}$ Delegacia Federal de Saúde e o Ipen (representado, no acordo, pela Diretoria Geral de Saúde Pública do Estado do Pará), que previa a cessão dos empregados do instituto para os inquéritos de malária na Amazônia. ${ }^{2}$

Valério Konder, responsável pela 2ª Delegacia Federal de Saúde, também foi convocado para integrar o trabalho de investigação sobre a malária. Em 30 de agosto, Evandro enviou telegrama ao interventor federal do Amazonas, Álvaro Maia, marcando para o quinto dia do próximo mês o início os trabalhos. ${ }^{3}$ Nessa etapa de preparação para os inquéritos ocorreram conflitos entre os profissionais convocados para o serviço. Evandro Chagas e Bichat de Almeida Rodrigues denominavam Konder de 'Messias', pois ele estaria atribuindo a si a responsabilidade pelo plano, em entrevistas publicadas em jornais locais. ${ }^{4}$ Parecia causar desconforto entre os envolvidos no planejamento do inquérito o fato de Konder conferir a si toda a autoria intelectual do trabalho, e claramente havia 
uma disputa sobre a direção dos trabalhos de investigação e controle da malária. ${ }^{5}$

Durante sua viagem à Amazônia, de 6 a 14 de outubro, Getúlio Vargas visitou o Ipen e declarou apoio ao projeto de saneamento da Amazônia, a ser realizado pelo Ministério da Educação e Saúde em conjunto com os profissionais do IOC. Vargas anunciou que estava em curso um plano de saneamento para a região durante uma cerimônia no $8^{\circ}$ destacamento militar de Belém. ${ }^{6}$ Segundo relatos da época, o presidente se interessou muito pelo projeto chefiado pelo superintendente do Sege. ${ }^{7}$ O principal objetivo de Evandro parecia ser o de prosseguir com a obra de seu pai, Carlos Chagas, que já estudara a região no início do século $\mathrm{XX} .{ }^{8}$ Em palestras e congressos, Evandro sempre apontava o inquérito na Amazônia como a continuidade do trabalho similar que seu pai realizara, em 1913, na região (Kropf, 2006, p.264).

Em 5 de novembro do mesmo ano foi oficializada aquela que seria a Comissão de Saneamento da Amazônia, da qual fariam parte Felipe Nery Guimarães, Evandro Chagas, Ernani Agrícola, João de Barros Barreto e Valério Konder. ${ }^{9}$ Em poucos meses, o inquérito reproduziu 20 mil fichas de doentes, abrangendo 48 cidades do Vale Amazônico. Com base nesses dados, foram levantadas informações sobre as condições de ocorrência da doença, incluindo características dos domicílios, características ambientais da área peridomiciliar, existência de focos de transmissão e, por fim, um mapeamento das áreas endêmicas.

Em 29 de outubro de 1940, Evandro enviou correspondência a L.L. Williams Jr., médico do National Institutes of Health, em Maryland, Estados Unidos, na qual abordava o trabalho de campo que ele e sua equipe desenvolviam. O conteúdo da missiva revela que todo o processo englobava duas metas, uma regional e outra mais ampla. Primeiro deveria estabelecer um plano de combate à malária na Amazônia para, no futuro, criar um serviço nacional dedicado à doença.

Dear Dr. Williams,

... It is the intention of our government to create a national service against malaria and we have been requested to draw up the general program for this service.

Our opinion was that nothing of permanent value could be done while we did not know the real condition of malaria in Brazil. We, therefore, told our minister of Public Health that no executive service should be stabilished before a preliminary investigation of two years carried out. We have already since last year been working in two of our field stations and two months ago, reconnaissance work has begun. We think that before the end of next year, a fairly efficient program can be made for our northern states, and in two years, we shall probably have the plans outlined for the whole country. ${ }^{10}$ 
O cronograma de trabalho estava pronto: no final de 1941, implementar-se-iam as ações de saúde e saneamento nos estados do Norte, para, em 1942, iniciar um plano de combate à malária que cobrisse todo o território nacional. Não por coincidência, o Ministério da Educação e Saúde passara, em 1940, por intenso processo de reforma para a criação dos Serviços Nacionais dedicados a doenças específicas, estabelecidos em 1941. A carta de Evandro Chagas revela que seu objetivo era um plano nacional de combate à malária e provavelmente seria ele o responsável pela direção do Serviço Nacional de Malária. Porém no dia 8 de novembro de 1940 a trajetória do diretor do Sege foi tragicamente interrompida por um desastre aéreo que resultou em sua morte no Rio de Janeiro.

Carlos Chagas Filho, irmão de Evandro, assumiu a direção do Sege e, a partir de um acordo entre o Instituto de Patologia Experimental Evandro Chagas (Ipeec, novo nome do Ipen) e a $2^{\underline{a}}$ Delegacia Federal de Saúde, finalizou os inquéritos sobre a incidência de malária no Vale do Amazonas. Todos os resultados foram processados no Ipeec e no Hospital Evandro Chagas, do IOC. ${ }^{11}$ Segundo Chagas Filho, o inquérito no Vale Amazônico terminou perto do tempo previsto. Para sua apuração foram examinadas mais de 22 mil lâminas, além de "incontáveis" fichas individuais. ${ }^{12}$ Em 4 de janeiro de 1941, o Sege enviou à Comissão de Saneamento da Amazônia os dados preliminares do inquérito epidemiológico. ${ }^{13} \mathrm{No}$ mesmo período, João de Barros Barreto recebeu também os resultados dos reconhecimentos preliminares feitos em Capanema, Vigia, Santarém, Borba, Maués, Parintins, Porto Velho e Guarajá-Mirim, para avaliar os dados que embasariam o Plano de Saneamento da Amazônia.

\section{O Plano de Saneamento da Amazônia}

Após a morte de Evandro Chagas, a Comissão de Saneamento da Amazônia foi reestruturada e passou a ser composta por João de Barros Barreto, Ernani Agrícola, Manuel J. Ferreira e Valério Konder. O posto ocupado por cada membro da equipe é revelador da importância dada ao plano por Vargas e Capanema: João de Barros Barreto era o diretor do principal órgão de saúde pública o país, o Departamento Nacional de Saúde (DNS); Ernani Agrícola foi nomeado, em 1941, diretor do Serviço Nacional de Lepra; Manuel José Ferreira era médico com especialidade em malariologia e Valério Konder era o responsável pela 2ª Delegacia Federal de Saúde.

Uma primeira apresentação do Plano de Saneamento da Amazônia foi enviada ao ministro Capanema em 14 fevereiro de 1941 e publicada em forma de relatório de recomendações, em dezembro de 1941, nos Arquivos de Higiene, periódico do DNS (Anexo). Embora a recomendação à comissão tivesse sido a de criar um plano de 
combate à malária, o conceito de saneamento apresentado no relatório ampliava esse objetivo:

Pela expressão "Saneamento" compreendeu a comissão o conjunto de atividades destinadas a melhorar as condições de vida e de saúde dos habitantes da Amazônia. Essas atividades podem ser resumidas em:

1) medidas visando o beneficiamento do meio, e atinentes em especial a serviços de abastecimento de água e remoção de dejetos (tarefa de saneamento propriamente dito) e

2) medidas de proteção de vida e da saúde a serem empreendidas por organizações sanitárias e de assistência médica (higiene, medicina preventiva, cuidado com os doentes). (Barreto et al., dez. 1941, p.191)

Barros Barreto e a Comissão pareciam compreender que a questão necessitaria ações governamentais mais integradas e estruturais. Combater exlusivamente a malária seria fazer uma obra incompleta de saneamento (Barreto et al., dez. 1941, p.192). Recomendaram a melhoria dos serviços de bioestatística, tidos como imprecisos, assim como a instalação de uma rede efetiva de Centros de Saúde e Postos de Higiene, já ineficientes em Manaus e Belém, também no interior (p.193).

Coadunando com o espírito centralizador do regime e com a visão de saúde pública de Barros Barreto, a Comissão indicava ser imperativo que o saneamento da Amazônia, por ser um "problema uno", deveria ficar sob "comando único". Assim, o DNS precisaria ser dotado de meios e poderes plenos, dada a amplitude do raio de ação sanitária na Amazônia. Acordos com órgãos e serviços estaduais e locais eram desejáveis porém "sempre sob rigoroso controle dos órgão federais" (Barreto et al., dez. 1941, p.192; grifos do original). A carência de técnicos também foi ressaltada e, para tal propósito, uma saída seria a formação de pessoal por meio de cursos de malariologia, que seguiriam o padrão do Departamento. Nesse primeiro relatório da Comissão há sobretudo preocupações em torno do saneamento básico das residências, consideradas bastante precárias pelos sanitaristas: "Precisam ser sem demora atendidos serviços básicos de saneamento, sem os quais não é possível qualquer obra completa de saúde pública; primordialmente os de águas e esgotos ao menos para os núcleos de 2.000 habitantes" (p.194).

Em relação à malária, a Comissão reconhecia ser impossível atuar concomitantemente em toda a região:

Afastada a idéia de se atender de logo o problema com igual intensidade em todo o vale do Amazonas, impôs-se a diretriz de pensar num saneamento ganglionar específico, conduzido 
diretamente pelo governo federal, ou seja, cuidar da redução e quiçá da erradicação da malária por zonas, escolhendo nelas um certo número de cidades ou mesmo núcleos menores, com valor econômico atual, significação estratégica ou perspectivas de progresso. As condições de muitos desses centros poderão ser bastante melhoradas; far-se-á, mesmo, uma verdadeira conquista sanitária de territórios agora praticamente inabitáveis, ou que com grande esforços estão sendo impulsionados 'apesar da malária', pagando a esta endemia um tributo injustificável (Barreto et al., dez. 1941, p.196).

O relatório da Comissão estava alinhado à concepção que o Estado Novo tinha da região: uma área inabitada e, além disso, inabitável, justamente por causa da malária. A conquista, além de física, deveria ser sanitária (Andrade, 2007). De acordo com essa premissa, os povos amazônicos enfim encontrariam a redenção após afastar esses problemas. O Estado seria o veículo dessa recuperação da Amazônia, mediante a ação coordenada e centralizada no DNS, graças aos Serviços Nacionais criados em 1941, principalmente os da malária, lepra e tuberculose. Nesse sentido, o Plano de Saneamento da Amazônia é uma das expressões da política de saúde que se conformava desde 1937 e se consolidava em 1941 (Fonseca, 2007; Hochman, 2001, 2005).

\section{A Guerra, o Serviço Especial de Saúde Pública e o abandono do Plano de Saneamento da Amazônia}

Um segundo relatório da Comissão de Saneamento da Amazônia foi publicado em abril de 1942 nos Arquivos de Higiene. São visíveis mudanças de concepção do Plano, fruto de novas conjunturas políticas nacionais e internacionais. Ao conhecer o plano que estava sendo desenvolvido pela Comissão em 1941, Getúlio Vargas teria feito críticas às propostas de saneamento para a região. Barros Barreto transcreveu as críticas de Vargas, em relatório de 1942:

[Getúlio Vargas]: O plano de que dá conta este relatório, embora bem lançado, não obedeceu exatamente ao que pretendo fazer pelo Saneamento da Amazônia. Não convém criar larga aparelhagem federal para isso, com numeroso pessoal e as conseqüentes obrigações, quando findo o trabalho. Será melhor ordenar a matéria, partindo dos serviços estaduais de saúde, que temporariamente passavam a ser, nesse particular, dirigidos por especialistas dos quadros federais e pelo governo federal subvencionados. Naturalmente, esse plano deve ser estudado em conjunto com os governos amazônicos e estabelecido, em forma de convênios de cooperação (Barreto, abr. 1942, p.39). 
As mudanças relacionavam-se aos ambientes políticos interno e externo: o Estado Novo começava a sofrer desgastes e Vargas buscava consolidar alianças futuras, e o Brasil rompia relações com o Eixo no início de 1942 e declarava guerra em agosto do mesmo ano. A partir das observações do presidente, que alterava a proposta de ação de saneamento mais centralizada e buscava a articulação política com as interventorias e elites políticas regionais, a Comissão apressouse em firmar convênios com os interventores federais dos estados amazônicos, propiciando uma maior participação dos Departamentos Estaduais de Saúde na execução do Plano. As ações prosseguiram, convocando-se para a Amazônia 584 antigos guardas sanitários do Serviço de Malária do Nordeste (SMNE), desmobilizado depois da Campanha contra o Anopheles gambiae (Barreto, abr. 1942, p.40).

Assim, Gustavo Capanema assinou, em 19 de novembro de 1941, com os interventores do Pará e do Amazonas, respectivamente José Carneiro da Gama Malcher e Álvaro Maia, os chamados 'convênios amazônicos', que previam a execução do Plano de Saneamento pelos respectivos Departamentos Estaduais da Amazônia, sob direção e fiscalização das Delegacias Federais de Saúde da $2^{\underline{a}}$ e $3^{\underline{a}}$ Regiões (Barreto, dez. 1941, p.55-56). Instituiu-se ainda, em Belém, um curso de malariologia e outro para visitadoras. Ademais, promoveram-se expedições para avaliar as condições de saúde dos habitantes. Os esforços eram todos direcionados para a profilaxia da malária, não sendo citadas outras doenças ou endemias (Barreto, abr. 1942, p.41). Profissionais como Ayroza Galvão e Alberto Carreira da Silva, responsáveis por relatórios na região de Manaus e Belém, foram alçados a cargos de coordenação nos respectivos Departamentos Estaduais de Saúde.

Concomitantemente aos trabalhos da Comissão e aos preparativos para implementação do Plano, o governo brasileiro assinava os chamados 'Acordos de Washington', em 3 de março de 1942, acordos militares e econômicos que, entre suas cláusulas, previam a fixação de preços para a compra de uma série de produtos brasileiros. Interessava aos norte-americanos aumentar a produção de matérias-primas de importância estratégica na situação de guerra vigente. A borracha adquiriu esse status porque os grandes centros produtores de látex estavam ocupados pelos países que constituíam o chamado Eixo (Itália, Japão e Alemanha). Segundo o acordo, para o aumento de produção da borracha deveria ser feito um prévio saneamento da região a ser explorada, o vale do Amazonas. Assim, criou-se em 1942 o Serviço Especial de Saúde Pública (Sesp), com o objetivo de controlar doenças (principalmente a malária) e dar assistência aos trabalhadores da borracha que chegariam à região. Dessa forma, os objetivos do Sesp tinham intersecções e competiam com o Plano de Saneamento da Amazônia, que vinha sendo elaborado desde 1940 pela comissão federal. 
Dez dias depois da assinatura desses acordos, um artigo anônimo intitulado "Convém distinguir" foi publicado no jornal carioca Correio da Manhã. De início o texto informava que, na reunião de consulta dos chanceleres americanos ocorrida no início do ano, ficou decidido que um grande número de médicos especialistas seria envolvido em uma ação ampla de saneamento das regiões produtoras de borracha, que estariam localizadas na Amazônia. E complementava:

O telégrafo nos anuncia a vinda de homens para planejar e dirigir. Que quer isso dizer senão que os nossos conhecedores do problema sanitário da Amazônia terão que se eclipsar, reduzidos talvez a colaboradores desses dirigentes. Ora, quem conhece o valor dos nossos técnicos e sabe que eles, no vasto cenário nacional, já têm dado sobejas provas de sua competência, fica realmente apreensivo quanto ao papel de subordinação que lhes ficaria reservado. ${ }^{14}$

A matéria ressaltava a alta qualificação dos técnicos brasileiros e discordava da presença de outros especialistas norte-americanos, considerando tal fato um desperdício de força, já que os especialistas estrangeiros poderiam ser aproveitados pelos próprios Estados Unidos, que também teriam necessidades. Questionava a autoridade que os americanos teriam, pois eles não eram especialistas em doenças tropicais. Para justificar a excelência brasileira no assunto, traçava um histórico da malária no Brasil e do pouco conhecimento estrangeiro sobre o assunto:

O Brasil sempre foi um país onde os estudos de medicina tropical tiveram grande desenvolvimento. E será fácil compreendêlo. Desde que a imigração africana trouxe para a Bahia as enfermidades tropicais reinantes no continente negro, a atenção dos médicos baianos se voltou para o problema. ... O paludismo, doença tropical por excelência e que extensa a quase totalidade do problema amazônico, possui inúmeros conhecedores ... que tem sido objeto de pesquisa e de campanhas profiláticas coroadas de êxito. Havendo uma dela no [rio] Madeira em que um técnico brasileiro foi quem salvou do naufrágio importante empreendimento que estava sendo sacrificado pela má orientação de um médico inglês. ${ }^{15}$ Com tudo isso, parece que a vinda de homens para "planejar e dirigir" o saneamento [de] zonas de cultura e de borracha representa pelo menos, na mais otimista das hipóteses e interpretações, uma dispersão de valores, num momento em que a capacidade individual pode ser fator decisivo para o êxito na guerra. ${ }^{16}$

Segundo Campos (2006, p.57), os americanos descobriram ter sido João de Barros Barreto o autor desse artigo. Mais parecia ser 
uma disputa de poder dentro do Ministério da Educação e Saúde, do que a expressão de desavenças quanto a concepções de sanitarismo, ou mesmo o levantar de uma bandeira nacionalista. Barros Barreto fazia parte de um grupo de profissionais da área de saúde pública que foram bolsistas da Fundação Rockefeller na Johns Hopkins School of Public Health, sendo consideravelmente influenciados pelo modelo de gestão de saúde e saneamento dos norteamericanos (Packard, Gadelha, 1994; Castro Santos, Faria, 2003, p.61-65). E a convivência com profissionais estrangeiros influenciou em parte o modelo de políticas públicas implementado pelo governo Vargas. Portanto a criação do Sesp como órgão autônomo e controlado pelos norte-americanos, para além das querelas nacionalsitas, ameaçava o 'todo-poderoso' diretor nacional de Saúde que sofreu nesse epísódio a maior derrota em sua excepcional carreira pública (Hochman, 2007).

Em abril de 1943 foi publicado o último relatório da Comissão de Saneamento da Amazônia, reconhecendo que, desde o início de 1942, o Plano sofrera um hiato devido à falta de recursos (Barreto, abr. 1943, p.43). O Plano de Saneamento da Amazônia, que mobilizou diversos profissionais ligados aos Departamentos Nacionais e Estaduais de Saúde e a institutos de pesquisas, não foi adiante. A execução do saneamento da Amazônia foi entregue ao Sesp. Barros Barreto, sem mencionar os Acordos de Washington ou o Serviço Especial de Saúde Pública, criticou o excesso de entusiasmo com o novo plano feito em convênio com os norte-americanos:

Do exposto resulta não dever ser elaborado um novo plano pelo DNS. Ficou provado que os serviços de saúde projetados estavam dentro das suas próprias atribuições. ... O que se sugere, pomposamente como grande novidade, foi o princípio estabelecido pela comissão: realizar trabalho desenvolvido de saúde pública nos núcleos habitados, dar sobretudo assistência ao restante da população. (Barreto, abr. 1943, p.29)

Uma comparação entre a agenda sanitária do Sesp e aquela que o DNS pretendia implementar na região mostra que, em linhas gerais, ambas se alinhavam ao projeto de ampliação da atuação da saúde pública no interior. O Sesp, assim como pretendia o DNS, montou unidades sanitárias, construiu e administrou escolas de enfermagem, hospitais, centros e postos de saúde, normatizou procedimentos através de seus manuais, estabeleceu convênios com estados e municípios, preocupou-se em formar mão-de-obra qualificada e promoveu a educação sanitária (Campos, 2006, p.55, 56). Entretanto o Plano era fruto de um esforço original e concertado entre profissionais, serviços e instituições nacionais para tentar superar os problemas sanitários da Amazônia nos moldes 
estadonovistas, ao passo que o Sesp era parte do esforço de guerra aliado, que não dava muita liberdade para o Brasil nas escolhas de suas políticas para a Amazônia. Nesse sentido, prevaleceram os interesses norte-americanos e a aliança militar regional. Porém, como indicou Barros Barreto, de fato não havia, em 1942, muitas diferenças entre as duas propostas, tanto que o Sesp utilizou pesquisas e inquéritos feitos pelo Sege, Ipen e pela Comisão de Saneamento da Amazônia (Andrade, 2007).

O Plano de Saneamento da Amazônia deve ser entendido também como parte do processo histórico da região amazônica no curso dos anos 30 e 40, quando ela passou a ser vista como um lugar a ser conquistado pelo poder central. Intelectuais do período ressaltaram a importância do binômio saneamento-colonização como aspecto fundamental a observar em qualquer política de povoamento implementada pelo governo. Assim, o Plano não esteva apenas associado aos médicos e sanitaristas que trabalharam em instituições científicas e serviços sanitários que atuavam na região, mas também ao próprio discurso do Estado Novo sobre a Amazônia e às políticas de saúde do governo Vargas. Acasos trágicos como a morte de Evandro Chagas, os abalos na legitimidade do regime e o envolvimento do Brasil no esforço de guerra ao lado dos Aliados modificaram dramaticamente o lugar da Amazônia no cenário nacional e internacional entre 1942 e 1945, e com isso inviabilizaram o Plano de Saneamento que vinha sendo gestado desde 1940. Essa história é um exemplo da combinação entre contextos políticos nacionais e internacionais em rápida transformação, associados a problemas sanitários graves e persistentes como as condições de vida e saúde das populações da Amazônia. 


\section{PLANO DE SANEAMENTO DA AMAZONIA}

(Exposição apresentada pela Comissão composta dos Drs. João de Bartos Barreto, Ernani Agricola, Manuel J. Ferreira e Valerio Konder)

Exmo. Sr. Ministro da Educação e Saude.

A Comissão do Plano de Saneamento da Amazônia deseja, de inicio, deixar frizados certos pontos, a seu ver fundamentais para o êxito da tarefa que se projeta empreender, e nos quais se alicerçou ao traçar as diretrizes que, após longa análise do problema, the pareceram mais recomendaveis.

1. Pela expressão "Saneamento", compreendeu a Comissão o conjunto de atividades destinadas a melhorar as condições de vida e de saude dos habitantes da Amazônia. Essas atividades podem ser resumidas em :

a) medidas visando o beneficiamento do meio. e atinentes em especial a serviços de abastecimento de água e remoção de dejetos (tarefa de saneamento propriamente dito); e

b) medidas diretas de proteção da vida e da saude a serem empreendidas por organizações sanitárias e de assistência médica (higiene, medicina preventiva, cuidados com os doentes).

Pela recomendaçăo de elaborar um plano "especialmente visancio a malária", entendeu a Comissão ser desejo do Governo dar a este problema particular atenção, pô-lo no plano de realce correspondente à sua importancla e signííicação. Mas nảo cuidar apenas dele, ou dele destacado de outros: de outros que se entrosam com o da malaria e de cuja solução contemporânea depende o próprio sucesso da campanha contra o impaludismo.

Estas considerações de ordem do:trinária, e sobre que tinham os membros da Comissão opinião firmada, ainda mais ressaltam, no caso em apreço, em face das circunstâncias especiais da Amazônia, numa precariedade impressionante de recursos sanitários e assistenciais.

De fato, quer considere apenas a situação atual dos núcleos existentes, quer atenda a qualquer programa que pretenda desenvolver, no sentido de impulsionar ou modificar as condiçöes econômico-sociais da região, em qualquer hipótese se encontrará sempre o Governo diante da premente necessidade de cuidar, antes de mais nada, da vida e da saude do homem.

$\cap$ entrelaçamento e a interdependência dos vários problemas de saude e de assistência nesse vasto território e alguns dos quais se focalizam na 
presente exposição, decorrem da finalidade una de todos eles. Não há, pois, como considerar isolada e independentemente fatores que colimam o mesmo objetivo.

A Comissão insiste nesse ponto, de vez que a execução de cometimentos isolados e independentes levaria a uma deformação do problema, tal como - definitu o Governo e foi compreendido pela Comissão. Visar só a malária será fazer obra incompleta de saneamento. Mas mesmo que se abra mão de tudo mais. e que se queira apenas cuidar do problema da malária - diretriz aliás que a Comissão tem sobejas razöes para desaconselhar ao Governo mesmo nesse caso - e em especial nas condições particulares da Amazônia - outros problemas de saude precisam ser abordados conjuntamente, para ver-se atendido de maneira satisfatória o do impaludismo. De fato, uma campanha intensiva contra a malária carece, entre outros auxilios, de uma ampla rede assistencial, do esteio de boas organizaçőes de saude pública, de obras contemporâneas de saneamento no sentido técnico do termo, de que se cuide de alimentar convenientemente as populaçôes afligidas pela doença, de que se tenham dados satisfatórios de bio-estatística.

Assim, pois, a divisão do problema naquelas duas linhas principais, traçadas pela portaria de V. Excia., decorre tão somente da necessidade, em obediência a ela, de definir o todo; e nãơ de que se possa admitir a possibilidade de dividir realmente um plano de saneamento em duas ou mais diretrizes independentes.

A Comissão entende, destarte, de importância basiliar seja encarado o Saneamento da Amazônia como um problema uno, e debaixo de um comando único. Este ponto de vista, tecnicamente aplicavel a qualquer circunstância similar, tem no caso em apreço indicação imperativa.

2. Este comando único não pode deixar de caber ao orgão técnicoadministrativo competente, o Departamento Nacional de Saude, que é precir so dotar de meios e poderes plenos, para uma ação da amplitude da que se planeja para a Amazônia. Obviamente ele preçisa contar com a cooperação te outros elementos do Governo Federal. fora mesmo da alçada do Ministério de que faz parte: assim, num exemplo, onde acaso se façam necessárias obras de grande hidràulica, deverá ter a colaboração do Departamento Nacional de Obras de Saneamento. Muitos dos referidos elementos teem interesse direto no problema do saneamento da Amazonia: basta citar o caso do S. N. A. P. P. e das iniciativas de colonização. Talvez mesmo não. se possa apontax o Ministério que não o tenha. Mas tambem precisa contar o D. N. S. com a colaboração estreita das organizaçōes de saude, dos Estados e do Territorio do Acre, em cujas máos convem deixar mesmo grande parte da execução do "plano de saneamento" segundo as normas adiante esboçadas. Mas sempre sob o rigoroso controle dos orgãos federais.

3.' Para assegurar grandes facilidades de açäo, indispensaveis em campanhas de larga envergadura, como a que se planeja, a Comissão solicita 
que, para a execução da parte propriamente federal da nova tarefa sejam concedidas: às autoridades que o Governo determinar, as facilidades constan tes dos artigos $1 .^{\circ}, 2^{\circ}, 4 .^{\circ}$ e $5 .^{\circ}$ do decreto-lei n. 1.143, de 9 de março de 1939. que institue normas para a aplicação dos créditos concedidos ao Conselho Nacional do Petróleo para comprovação de despesas, admissão de pessoal.

Para a parte de execução estadual, convirı fosse o auxilio do Governo Federal concedido em prestaçōes, para aplicação fixada no ato da entrega e devidamente controlada; outra fórmula recomendavel seria a do pagamento das despesas pelas Delegacias Fiscais do Tesouro Nacional, à vista de documentos previamente examinados e visados pelas autoridades sanitárias federais competentes.

4. ${ }^{\circ}$ Estabelecidos esses primeiros pontos fundamentais, reconhecida muito especialmente a autoridade que deve caber ao Departamento Nacional de Saude e apontadas as grandes facilidades de ação, que devem ter os elementos executivos nele integrados, a Comissão principalmente por estas duas razöes se exime de formular planos com o apuro de minúcias, e discríminar pequenas parcelas orçamentárias, por tipos pormenorizados de trabalhos e pelas diversas localidades a atender. Se procedesse de outro modo, eștaria seguramente tolhendo a ação do orgão executor que, ao demais, terá no próprio andamento dos serviços e nas facilidades que encontrar, ou the forem concedidas, melhores elementos para a fixação de um programa detaJhado e para a distribuição e emprego das verbas disponiveis. de acordo com as necessidades da prática.

No que se vai seguir, cuidou destarte a Comissão apenas de focalizar alguns aspectos do problema vastíssimo do "Saneamento da Amazônia", e de traçar as primeiras diretrizes gerais.

Aponta tambem as importâncias, que lhe parecem indicadas para um avanço inicial muito forte, no caminho da realizaçăo dessa grande tarefa que - Governo resolveu empreender.

Todo o assunto foi cuidadosamente discutido pela Comissão em 32 reuniões. Houve ocasião de compulsar a documentação disponivel, tendo sido de valor a contribuição e os esclarecimentos trazidos pela Divisão de Saude Pública do Departamento Nacional de Saude, pela Delegacia Federal de Saude da 2." Região e pelo Serviço de Grandes Endemias. A Comissão examinou mesmo, com o maior interesse e cuidado, os dados recebidos de 30 dos 51 reconhecimentos de malária feitos na região, em intima colaboração, pelos referidos Serviço e Delegacia, e cuja apuração, iniciando-se ao tempo do pranteado Dr. Evandro Chagas, o seu irmão Dr. Carlos Chagas Filho completa presentemente.

A) Providência capital, e mesmo preliminar, è a preparação do pessoal técnico e auxiliar para toda a tarefa sanitária, que é preciso empreender na Amazônia. Embora possam ser desde logo mobilizados, com remuneração A. H. F. 13 
compensadora, elementos de valor para a campanha nos seus diversos setores, a Comissão acha indispensavel :

a) a realização de cursos de malariologia dı padrão D. N. S. para tếcnicos e auxiliares;

b) a designação obrigatória, de acordo com as autoridades federais, de técnicos estaduais para seguirem cursos de especialização, a deverem ser organizados pela União, particularmente para laborałoristas, engenheiros sanitários, leprologistas, tisiologistas, estatistas, puericultores, nutricionistas, psiquiatras, etc. e respectivos auxiliares;

c) a organização, em Belem, de novos cursos intensivos de saude pública, quer para o aperfeiçoamento de técnicos estaduais quer, e como medida de emergencia, para o ingresso na respectiva carreira;

d) a instalação imediata em Belem de uma escola de enfermagem, padrão Ana Neri, tendo cursos tambem para visitadoras e atendentes, destinados aos serviços de saude pública, de hospitais e ambulatórios de assistência.

A Comissão estima necessária uma verba de $1.000: 000 \$ 000$ para esse fim.

B) E indispensavel a realização intensiva de pesquisas sobre problemas de saude pública, especialmente no campo da malária. Inúmeras questớes, ainda nâo esclarecidas, desafiam os pesquisadores e entravam o trabalho dos técnicos. Por isso, deverão as pesquisas ter cunho eminentemente prático, estar entrosadas com as atividades de rotina. Comandadas, destarte, por um mesmo orgāo. Isto não impede que este orgão, devidamente autorizado, cometa parte da tarefa, por acordos, a técnicos ou organizações de reconhecido valor científico, até de fora do Brasil.

A Comissão considera necessário destinem-se à pesquisa 1.000:000\$000, para pagamento do pessoal, os gastos com as adaptações e instalações necessárias e as despesas de manutenção.

C) Precisam ser sem demora atendidos serviços básicos de saneümento, sem os quais não é possivel qualquer obra completa de saude pública: primordialmente os de águas e esgotos ao menos para os núcleos de mais de 2.000 habitantes. Nesse particular a situação é de grande precariedade em toda a Amazônia; as próprias capitais pedem providências decisivas. O Governo Federal deve promover a solução desses problemas. Para isso estudos de ordem técnica e financeira precisam ser sem demora empreendidos. É justo que a União, com as facilidades de que dispõe, os faça realizar por sua conta. Desde logo com o estudo e organização de plantas e projetos das obras necessárias, para abastecer de água de boa qualidade as populações, e dispor convenientemente as suas águas residuárias; dará ainda sugestões práticas para a realização dos trabalhos. Esta tarefa pode ficar a cargo do Serviço de Águas e Esgotos. Um entendimento da Comissão com o Diretor desse Serviço, o engenheiro Alberto Pires Amarante, evidenciou que tais 
estudos podem ser executados com o dispêndio de 150:000\$0; em nove meses deverão estar eles ultimados em, pelo menos, 25 núcleos de mais de 2.000 habitantes.

D) Tornam-șe imprescindiveis uma nova ampliação, e sobretudo a melhoria das atividades, dos dois Departamentos estaduais de Saude Pública, que passaram já há alguns anos por oportunas reformas; precisam tambem ser organizados serviços correspondentes no Território do Acre.

E para todos é premente conseguir bons técnicos, ter recursos materiais, estabelecer $e$ fazer executar normas rigorosas de trabalho. Todos carecem principalmente de boas equipes técnicas, tanto para a direção como para a execução, e elas precisam ser escolhidas, e controladas pelo orgão federal. Mas necessitam tambem de que se aprimorem os serviços, quer os centralizados, como os de bio-estatistica, educação sanitária, laboratório, epidemiologia, engenharia sanitária, quer os de natureza distrital, providos de uma rede efetiva de Centros de Saude e Postos de Higiene. Se estes serviços nas capitais precisam ser melhorados, é ainda mais urgente a instalaçăo das referidas unidades no interior. localizadas estrategicamente no ponto de vista sanitário. Cabe-lhes grande parte da tarefa que é preciso intensificar, dentro de um plano harmônico de ação, federal e estadual, para dar combate à tuberculose, à lepra, à ancilostomose, às doenças venéreas, a doenças contagiosas agudas, para cuidar da higiene da criança em todos os seus áspectos, citando apenas algumas das atividades importantes de saude pública. Alem do fornecimento de técnicos, a União dive conceder um auxilio largo, e rigorosamente controlado, para a ampliação e melhoramento dessas organizações de saude pública. Convem destinar a esse fim 1.000:000\$0, e serão mobilizados para a Amazônia, com vencimentos compensadores - mesmo em bases de exceção - vários especialistas.

E) Não se deve pensar em conseguir cousa alguma de verdadeiramente util sem ter dados, e o controle regular de um bom serviço de bioestatistica. Ele é atribuição das repartições estaduais, que precisam porem estar articuladas intimamente com o orgão correspondente do D. N. S. encarregado desta tarefa. Mas, na verdade, todo o êxito está na dependência inicial de uma coleta continua, permanente, incessante de dados verdadeiros. Depois de entendimentos com o secretário geral do Instituto Brasileiro de Geografia e Estatistica, Dr. Teixeira de Freitas, fixou a Comissão como indispensaveis os seguintes pontos :

a) melhorar a qualidade dos dados de registo, para o que são particularmente indispensaveis o controle de parteiras e curiosas e, em todas as localidades em que houver médico, a verificação dos óbitos ocorridos sem assistência médica, com autópsia obrigatória desses casos nos núcleos maiores:

b) fazer executar em toda a região as determinações constantes do projeto organizado pelo Conselho Nacional de Estatística com o D. N. S., 
constante da resolução 106 (de 19-VII-938) daquela entidade, e que aliàs já é lei nos Estados do Amazonas e do Pará;

c) delegar autoridade aos orgãos sanitários federais, para o controle rngoroso dos oficiais de registo civil e dos agentes municipais de estatistica, chegando até a proposta de sua substituição, quando não desempenharem devidamente as funçôes respectivas;

d) conseguir facilidades, inclusive auxílio financeiro, para os serventuários citados na alinea $c$ com o intuito de obter a remessa pronta de informes estatisticus;

e) dispor de técnicos especializados para acompanhamento e tiscalizar çâo da tarefa de bio-estatistica.

F) Malária - Afastada a idéia de se atender de logo ao problema, com igual intensidade em todo o vale do Amazonas, impôs-se a diretriz de pensar num "saneamento ganglionar especifico", conduzido diretamente pelo Governo Federal, ou seja cuidar da redução e quiçá da erradicação da malária por zonas, escolhendo nelas um certo número de cidades ou mesmo núcleos menores, com valor econômico atual, significação estratégica ou perspectivas de progresso. As condiçốes de muitos desses centros poderão ser bastante melhoradas; far-se-á, mesmo, uma verdadeira conquista sanitária de territórios agora praticamente inabitaveis, ou que com grandes esforços estão sendo impulsionados "apesar da malária", pagando a esta endemia um tributo injustificavel. Só isto representará um resultado prático, cujo valor é excusado encarecer.

E bem verdade que a montagem de uma boa organização anti-malárica exıge tempo e recursos bastantes. Mas, tambem só com o concurso desta máquina é que estará o Governo habilitado a atender à proteção do homem, onde e quando o exigirem outras iniciativas que decidir tomar com a finalidade do progresso do vale amazônico.

Graças em grande parte às contribuições trazidas pelo Serviço de Grandes Endemias e pela Delegacia Federal de Saude da 2.a Região, viu-se justi ficada a proposta de aplicação no combate intensivo à malária de uma verba de 28.000:000\$0, de crédito especial utilizavel em dois exercícios, como as demais verbas solicitadas.

Esta indicação de 28.000:000\$0 decorreu tambem das seguintes razסes:

a) conhecimento do custo da organização $e$ andamento de campanhas intensivas, inclusive e especialmente a do Serviço de Malária do Nordeste;

b) existência na regiảo de duas grandes cidades (Manaus e Belem). cuja inclusão se impõe no rol das que devem ser imediatamente trabalhadas;

c) condições meteorológicas da Amazônia, entre as quais não se encontra, como no Nordeste, a grande aliada seca;

d) necessidade de levar em conta o tratamento da malária, tambem a ter de ser aplicado intensamente em numerosas localidades, em que o serviço anti-anofelínico não for imediatamente realizado. 
Com a referida verba serão feitas a montagem da máquina central de administração, a instalação e desenvolvimento de uma rede progressiva de serviços, conduzidos segundo a prática dos métodos aconselhaveis para o combate intensivo à malária, e que se iniciaria pelas localidades abaixo ressaltadas como mais merecedoras, desde logo, desse trabalho, em face dos elementos de que dispôs a Comissão.

Constituirá parte inciispensavel ao trabalho de malária e realização sistemática de observações meteorológicas, em pontos escolhidos pelas autoridades sanitárias federais, para o que o Departamento especializado do Ministério da Agricultura fará instalar as estações necessárias.

A Comissão pensa que o trabalho anti-malárico intensivo deve ser iniciado em quatro setores regionais, compreendendo cada qual várias localidades, num total de 12:

a) Núcleo Belem, abrangendo serviços em Belem, Capanema, Vigia, Soure-Salvaterra ;

b) Núcleo Manaus, compreendendo Manaus. Maués e Parintins;

c) Núcleo Santarem. com Santarem, Óbidos e Alenquer;

c) Núcleo Manaus, correspondendo Manaus, Maués e Parintins;

d) Núcleo Porto Velho, com serviço em Porto Velho e Guajará Mirim.

Numa segunda etapa viriam mais 15 localidades. Assim estender-se-iam os serviços:

a) no Núcleo Belem, a Santa Isabel, Castanhal, Breves, Curuçá e Vizeu;

b) no Núcleo Santarem, a Monte Alegre;

c) no Núcleo Porto Velho, a Borba, Manicoré e Humaitá.

$\mathrm{E}$ se iniciariam nu.

d) Núcleo Guiana, por Macapá;

e) Núcleo Tocantins, em Marabá, Alcobaça, Baião e Mocajuba;

f) Núcleo Rio Negro, em Barcelos.

A vista dos dados disponiveis dos reconhecimentos, parecem à Comissão menos dignas de consideração presentemente no ponto de vista de indicação para a campanha anti-malárica, as seguintes localidades: Bragança, IgarapéAssà, Cametá, Abaeté. É possivel, porem, que os elementos, que faltam dos reconhecimentos, venham alterar esse primeiro juizo emitido pela Comissão.

A Comissão salienta terem sido ainda objeto dos reconhecimentos sobre a extensăo da malária, custeados e realizados pelo Serviço de Grandes Endemias e pela Delegacia Federal de Saude da 2. ${ }^{a}$ Região, mais 19 localidades tambem escolhidas em razão de suas condiçŏes econômicas ou geográficas, inclusive por interesse estratégico.

Essas localidades são as seguintes: Itacoatiara, Chaves, Amapá, Boa Vista do Rio Branco, Altamira, Coari, Tefé, Fonte Bôa, Tabatinga, Lábrea. Boca do Acre, Rio Branco, Xapuri, Brasilia, Sena Madureira, São Felipe. Cruzeiro do Sul, Feijó e Seabra. 
Só quando conhecidos os resultados desses reconhecimentos é que convem decidir sobre a indicação e a oportunidade de estender a campanha aos referidos núcleos. A Comissão, instada a concluir os seus trabalhos, deixa assim em aberto a solução deste caso, o que em nada aliás alteraria as diretrizes gerais sobre o saneamento da Amazônia.

G) A Comissão não se furta ao dever de salientar que os problemas de tuberculose e lepra, mais postos em foco atualmente, não se podem restringir à construção e instalação de leprosários, sanatórios e preventórios. Necessário se torna fornecer recursos para a sua manutenção e funcionamento, bem como para a execução de trabalhos não menos importantes, tais como censo rigoroso de doentes, obtenção de técnicos especializados com bons auxiliares, inclusive enfermeiras, visitadoras e atendentes, recursos para o diagnóstico, instalação das redes de dispensários para este fim, para vigilância e tratamento, práticas de imunização quando indicadas. O Governo Federal precisa assistir técnica e financeiramente aos Estados da Amazônia para a consecuçăo de todos estes empreendimentos. A Comissão estima em 2.800:000\$0 a verba para fazer face a esses encargos.

H) O problema da alimentação está sendo focalizado por toda a parte. Os dados, embora esparsos que se conhecem para a Amazônia, fazem-no incluir entre os que exigem uma atençăo desvelada. A Comissāo pensa serem oportunas para atendê-lo as seguintes providências:

a) a articulação de entidades administrativas interessadas no assunto para a fixação e execução de uma politica de alimentação dirigida, indispensavel ao equilibrio econômico e à valorisação fisiológica de elemento humano;

b) a realização de inquéritos econômico-sanitários, para precisar os hábitos e as verdadeiras condiçöes alimentares nas diversas regiōes, apurando seus principais defeitos, a extensão do estado de má nutrição. das doenças de carência e estados pre-carenciais, nas várias classes de população;

c) a promoção de medidas tendentes a fomentar a produção e o consumo de alimentos de real valor nutritivo;

d) a organização de padrōes de alimentação balanceada, para as diversas classes de populaçáo;

e) a realização de pesquisas sobre o valor nutritivo de espécies pouco conhecidas da fauna e flora da Amazônia.

I) A seu turno a rede assistencial é precarissima, impressionantemente deficiente na Amazônia. Parece imprescindivel cuidár de estruturá-la embora rudimentarmente de começo, para ampliá-la pouco a pouco, melhorando o seu aparelhamento. Mas é tão dispendiosa e demorada a organização de uma rede de hospitais, que a Comissão pensa ser mais razoavel e prático instalar, de início, e manter sob controle rigoroso, não só postos para dar alguma assistência sanitária e socorros de urgência, como ainda ambulatórios, já melhor equipados e providos de facilidades para acomodações de doentes. 
Crê a Comissão de vantagem um entendimento com as Missões Religiosas já em trabalho na região, sobre a possibilidade de ficarem, nas zonas do Acre, do Amazonas e mesmo do Pará, em que possam operar, com o en cargo dessas unidades de assistência. Fora dai a tarefa será da alçada estadual. Mas quer num, quer noutro caso, ficará sob a fiscalização e orientação das autoridades sanitárias federais. Aos poucos as unidades irão dando lugar a pequenos hospitais. Desde logo, porem, um certo número destes estabelecimentos, com o mínimo de 30 leitos, serão instalados e os existentes de presto melhorados. Serão hospitais de tipo polivalente, fora das capitais; mas até nesses centros maiores, obedecerão, em parte, à mesma norma moderna de organização. Assim é que, alem de fazerem assistência médico-cirúrgica, terão setores especiais para os tuberculosos, as puérperas, as crianças.

Para facilidade do serviço, especialmente de fiscalizaçâo, essas unidades de assistência distribuir-se-ão em regióes: sete no Acre e Amazonas (Rio Branco, Rio Negro, Rio Juruá, Rio Purús, Rio Madeira, Alto Amazonas, Baixo Amazonas); nove no Pará (duas no Baixo Amazonas, no Alto e Baixo Tocantins, Rio Xingú, na zona de Belem, na linha Bragantina, na Ilha de Marajó, na Guiana).

Dentro dessas diretrizes, o setor de assistência, que de muito aliás irá valer à campanha contra a malária, comportaria as seguintes providências imediatas :

a) auxilio extraordinário ou melhoria de subvenção para os hospitais de Porto Velho, Manaus, Santarem, Óbidos e Belem (5);

b) início da construção de hospitais em Rio Branco, Cruzeiro do Sul, Itacoatiara e Bragança (4);

c) instalação de ambulatórios em Boa Vista do Rio Branco, Barcelos, S. Gabriel, Taracuá, Jauaretê, Parí, João Pessoa, Seabra, Lábrea, Boca do Acre, Sena Madureira, Xapuri, Humaitá, Manicoré, Tefé, Tabatinga, Coari, São Paulo de Olivença, Parintins, Maués, Manacapurú, S. Miguel do Guaná, Curuçá, Cametá, Marabá, Alcobaça, Soure, Breves, Cachoeira, Altamira, Faro, Oriximiná, Itaituba, Oyapock, Macapá e Amapá (36);

d) instalação de postos em Caracarai, Moura, Carauari, Feijó, no Alto Juruá, no Moa, em Brasilia, Porto Acre, Oriente, no Alto laco, em Borba, Fonte Boa, na Foz do Jutai, em Codajás, Vizeu, Salinas, Maracanã, Marapanin, S. Caetano, Vigia, S. Domingos, Ourem, Abaeté, Mocajuba, Baião, Conceição do Araguaya, Chaves, Anajás, Muaná, Porto de Mós, Gurupá, Alenquer, Monte Alegre, Prainha (34).

Verba proposta (salvo a parte de subvenções) 1.600:00\$0.

São estas, Sr. Ministro, as ponderações que a Comissão tem a honra de submeter à consideração do Governo, como diretrizes gerais para o Plano de Saneamento da Amazônia.

Atenciosas saudaçöes.

14 de fevereiro de 1941. 
RÔMULO DE PAULA ANDRADE E GILBERTO HOCHMAN

\section{NOTAS}

${ }^{1}$ Não há uma data precisa para a convocação de Evandro Chagas à Comissão de Saneamento da Amazônia. O documento com a data mais adiantada é um relatório entregue ao IOC pelo médico Francisco Cerqueira, datado de 6 de junho de 1940, em que este avisa ao Instituto da convocação de Evandro à Comissão. Fundo Família Chagas/Documentos de Evandro Chagas (doravante denominado FFC), caixa 1. (Casa de Oswaldo Cruz/ Fundação Oswaldo Cruz - doravante denominado COC/Fiocruz).

2 “Bases do Acordo que entre si firmam a Diretoria Geral de Saúde Pública do Estado do Pará, a Delegacia Federal de Saúde da $2^{\text {a }}$ Região e o Instituto de Patologia Experimental do Norte, para o fim expresso e uma ação conjunta para o combate à Malária". FFC, caixa 2 (COC/Fiocruz).

3 Correspondência de Evandro Chagas para Álvaro Maia, 30 ago. 1940, FFC, caixa 2 (COC/Fiocruz).

4 Correspondência de Evandro Chagas para Bichat de Almeida Rodrigues, 4 out. 1940, FFC, caixa 6 (COC/ Fiocruz).

5 Embora passados mais de 60 anos, as referências biográficas lhe atribuem todos os créditos da elaboração de um certo "plano de saneamento da Amazônia": "Como delegado na 2a região, Valério Konder elaborou um plano de saneamento da Amazônia, e em 1943 apresentou ao presidente Getúlio Vargas. Getúlio gostou do plano, mas disse que não poderia executá-lo porque o Brasil entrara na guerra". (Escorel, 2000, p.68-69); "[Valério Konder] trabalhou de 1938 a 1944 como médico sanitarista do MES nas regiões norte e nordeste ... nessa época, elaborou um plano de saneamento para mais de 50 cidades do Pará, cuja execução foi suspensa devido à entrada do Brasil na II Guerra Mundial em 1942" (Abreu et al., 2000).

6 Correspondência de Cardoso Fontes a Evandro Chagas, 10 out. 1940. FFC, caixa 8 (COC/Fiocruz).

7 Cecílio Romaña, "Vida e obra de Evandro Chagas", 10 nov. 1940. FFC, série Trajetória Profissional/Trabalho de Terceiros, 19401110, p.3 (COC/Fiocruz).

8 O primeiro "Plano de Saneamento da Amazônia" foi feito por Carlos Chagas em 1913. Comissionado pela Superintendência de Defesa da Borracha, Chagas propôs um plano de profilaxia para a região, a partir de dados obtidos durante a verificação de saúde dos seringueiros. Durante cinco meses, Chagas e os pesquisadores Pacheco Leão e João Pedroso percorreram cidades, vilas e seringais procurando uma saída para a queda de produtividade da borracha, por meio da melhoria das condições de saúde dos seringueiros. Para Chagas, a malária era considerada o principal inimigo dessa atividade e se conseguisse acabar ou pelo menos controlá-la, a produção cresceria de novo e reocuparia a ponta do mercado mundial. Seu "Plano geral da campanha Sanitária a se empreender no Vale do Amazonas" nunca foi posto em prática (Chagas, Cruz, Peixoto, 1972).

9 FFC, série Correspondência, 1940092/n.49 (COC/Fiocruz).

10 Correspondência de Evandro Chagas para L. L. Williams, 29 out. 1940, FFC, caixa 7 (COC/Fiocruz).

11 Relatório de Carlos Chagas Filho ao ministro da Educação e Saúde, 27 ago. 1942, FFC, caixa 8, p.3 (COC/ Fiocruz).

12 Relatório de Carlos Chagas Filho ao ministro da Educação e Saúde, 27 ago. 1942, FFC, caixa 8, p.4 (COC/ Fiocruz).

13 Correspondência ao Ministério da Educação e Saúde, 4 jan. 1941, FFC, caixa 8 (COC/Fiocruz).

14 Correio da Manhã, 13 mar. 1942, p.13. (Biblioteca Nacional, Seção de Periódicos).

15 Provavelmente a referência é à construção da Ferrovia Madeira-Mamoré, na Primeira República.

16 Correio da Manhã, 13 mar. 1942, p.13. (Biblioteca Nacional, Seção de Periódicos). 


\section{REFERÊNCIAS BIBLIOGRÁFICAS}

Abreu, Alzira Aves de et al. 2000

Andrade, Rômulo de Paula

2007

Barreto, João de Barros abr. 1943

Barreto, João de Barros abr. 1942

Barreto, João de Barros et al. dez. 1941

Campos, André Luiz Vieira.

2006

Castro Santos, Luiz

Antonio de; Faria, Lina

Rodrigues de

2003

Chagas, Carlos; Cruz,

Oswaldo; Peixoto,

Afrânio

1972

Escorel, Sarah

2000

Fonseca, Cristina

M. Oliveira

2007

Hochman, Gilberto 2007

Hochman, Gilberto 2005

Hochman, Gilberto 2001

Kropf, Simone P. 2006

Packard, Randall;

Gadelha, Paulo Ernani 1994
Dicionário histórico-biográfico brasileiro pós-1930. Rio de Janeiro: Centro de Pesquisa e Documentação de História Contemporânea do Brasil/ Fundação Getulio Vargas.

A Amazônia vai ressurgir!: saúde e saneamento na Amazônia do primeiro governo Vargas (1930-1945). Dissertação (Mestrado) - Programa de Pós-graduação em História das Ciências e da Saúde/Casa de Oswaldo Cruz/Fiocruz, Rio de Janeiro.

Saneamento da Amazônia. Arquivos de Higiene,

Rio de Janeiro, v.13, n.1, p.21-29.

O Saneamento da Amazônia. Arquivos de Higiene, Rio de Janeiro, v.12, n.1, p.37-56.

Saneamento da Amazônia. Arquivos de Higiene, Rio de Janeiro, v.11, n.1, p.191-199.

Políticas internacionais de saúde na era Vargas: o Serviço Especial de Saúde Pública, 1942-1960. Rio de Janeiro: Ed. Fiocruz.

A reforma sanitária no Brasil: ecos da Primeira República.

Bragança Paulista: Edusf.

Relatório sobre as condições médico-sanitárias do vale do Amazonas. In: Sobre o saneamento da Amazônia. Manaus: P. Daou.

Saúde pública - utopia de Brasil.

Rio de Janeiro: Relume-Dumará.

Saúde no governo Vargas (1930-1945): dualidade institucional de um bem público. Rio de Janeiro: Ed. Fiocruz.

João de Barros Barreto. In: Bynum, Wiilliam F.; Bynum, Helen (Ed.). Dictionary of medical biography. Wesport: Greenwood Press. p.160.

Cambio político y reformas de la salud pública en Brasil: el primer gobierno Vargas (1930-1945). Dynamis - Acta Hispanica ad Medicinae Scientiarumque Historiam Illustrandam, Granada, n.25, p.199-226.

A saúde pública em tempos de Capanema: inovações e continuidades. In: Bomeny, Helena (Org.). Constelação Capanema: intelectuais e políticas. Rio de Janeiro: Ed. FGV, p.127-151.

Doença de Chagas, doença do Brasil: ciência, saúde e nação.

Tese (Doutorado) - Programa de Pós-graduação em História/ Universidade Federal Fluminense, Niterói.

A land filled with mosquitos: Fred L. Soper, the Rockefeller Foundation and the Anopheles gambiae invasion of Brazil. Parasitologia, v.36, p.197-213. 


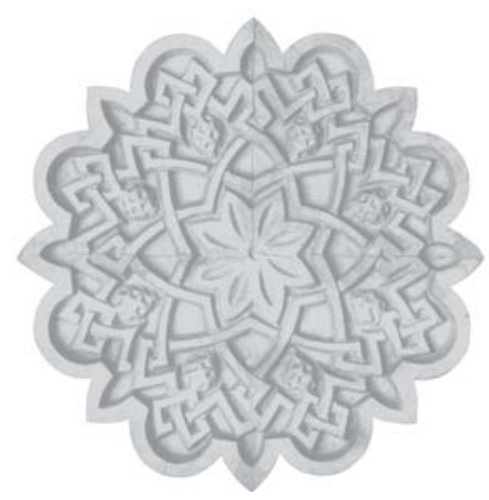

